\title{
Assessment of cyclic fatigue resistance of Protaper Next and WaveOne Gold in different kinematics
}

\author{
Amira Galal Ismail ${ }^{1 *}$ D, Manar Galal ${ }^{1}$ and Nehal Nabil Roshdy ${ }^{2}$
}

\begin{abstract}
Background: The purpose of the current study was to inspect and compare the influence of applying continuous rotation and reciprocation motions on the cyclic fatigue resistance of Protaper Next (PTN) file (X2) and WaveOne Gold (WOG) Primary file in simulated canals. Twenty Protaper Next files(X2) and 20 WaveOne Gold Primary files were included in this study. A cyclic fatigue testing device was employed to test the cyclic resistance of each file in different motions. The testing device has an artificial custom-made stainless-steel canal with a $60^{\circ}$ angle of curvature and a 2-mm radius of curvature. The files were randomly divided into 4 groups; group 1: PTN in continuous rotation, group 2: PTN in reciprocation, group 3: WOG in continuous rotation and group 4: WOG in reciprocation. All the instruments were rotated until fracture occurred, and the time to fracture was recorded in seconds using a digital chronometer. The number of cycles to fracture (NCF) was calculated. The data were analyzed statistically $(p<.05)$.
\end{abstract}

Results: Results represented that when using either continuous rotation motion or reciprocating motion, WOG files showed a significantly longer time until failure than PTN files $(p<0.001)$. The time till fracture increased significantly, when using both types of files with a reciprocating filing motion.

Conclusion: Within the confinement of this study, WOG file in reciprocation showed higher cyclic fatigue resistance than PTN in both continuous rotation and reciprocating motion. The reciprocating motion enhances both files behavior in terms of cyclic fatigue resistance.

Keywords: Continuous rotation, Cyclic fatigue ProtaperNext, Reciprocation, WaveOne Gold

\section{Background}

The behavior of endodontic instruments is considered a critical factor in achieving safe root canal shaping. Nickel titanium $(\mathrm{NiTi})$ rotary instruments showed superiority over stainless steel files in clinical practice. The NiTi instruments provided greater flexibility, super elasticity, and increased cutting efficiency (Peters 2004). However, unexpected instrument fracture may occur during root canal shaping. Rotary NiTi files show two types of failure modes: torsional failure and cyclic fatigue failure.

\footnotetext{
* Correspondence: amiragalal@gmail.com

${ }^{1}$ Restorative and Dental Materials Department, National Research Centre (NRC), El Bohouth St., 12622 Dokki, Giza, Egypt

Full list of author information is available at the end of the article
}

Torsional failure takes place when the tip of the file is bound to dentin while its shank is still rotating. Cyclic fatigue occurs when part of the file is bound to dentin while subjected to cycles of compression/tension strain in the area of maximum root canal curvature (Sattapan et al. 2000; Parashos and Messer 2006). Cyclic fatigue is considered the principal cause of NiTi instrument separation especially in canals with acute-angles and short radius of curvature (Pruett et al. 1997).

In this context, improving methods for cyclic fatigue resistance have been proposed, including modifying the chemical composition of the $\mathrm{NiTi}$ alloy, changing the manufacturing process, providing novel cross-sectional designs, thermomechanical processes, and kinematics 
(Shen et al. 2013; Karataş et al. 2016). Researchers have claimed that reciprocating motion augment the fracture resistance of endodontic rotary files during instrumentation by working continuously below the instruments' elastic limit, thereby prolonging their cyclic fatigue resistance when compared with their usage in continuous rotation (Castelló-Escrivá et al. 2012; Plotino et al. 2015).

ProTaper Next (PTN; Dentsply Maillefer, Ballaigues, Switzerland) is a NiTi rotary system that has variable taper and an off-centered rectangular cross-sectional design. This design feature creates an enlarged space for debris removal as suggested by the manufacturer. The M-wire alloy used in the instrument manufacturing improves the file flexibility, while retaining the cutting efficiency resulting in better cyclic fatigue resistance (Elnaghy and Elsaka 2014).

WaveOne Gold (WOG; Dentsply Maillefer, Ballaigues, Switzerland) is a reciprocating single-file rotary system. The WOG combines the original WaveOne reciprocating instrument technique and the metallurgical advancements of a gold thermal treatment, which gives the file a characteristic golden appearance. It has modified dimensions and geometry through an off-centered parallelogram cross-section. It has been stated that the gold heat treatment improved the file cyclic fatigue resistance of WOG when compared with other reciprocating or continuous motion rotary systems (Ozyurek 2016). The heat treatment of the gold is implemented by heating the file manually, then cooling it slowly, unlike the heat treatment of the M-wire technology which is premanufactured. According to the manufacturer, this type of heat treatment augments the elasticity of the file (Webber 2015).

There is only limited information about the impact of rotation and reciprocating motion on the cyclic fatigue resistance of files made to rotate in only one motion. The purpose of present study was to compare the cyclic fatigue resistance of Protaper Next and WaveOne Gold files when used with continuous rotation and reciprocating motion to evaluate the effect of the motion on the lifespan of the tested instruments. The null hypothesis was that the cyclic fatigue performance of both files when operated with different motions would not differ.

\section{Methods}

\section{Sample size}

The sample size was calculated based on the results of Plotino, G., et al. (Plotino et al. 2012). Adopting an alpha $(\alpha)$ level of $0.05(5 \%)$, a beta $(\beta)$ level of 0.20 $(20 \%)$, i.e., power $=80 \%$, and an effect size $(d)$ of (1.92) the predicted sample size was a total of (12) samples. Sample size calculation was performed using G*Power version 3.1.9.7

\section{Cyclic fatigue test}

Forty NiTi rotary instruments were inspected under a stereomicroscope (Axio Zoom.V16; Carl Zeiss, Jena, Germany) for defects or deformities, and none was discarded. All the instruments were $25 \mathrm{~mm}$ long. The instruments were divided in the following groups $(n=10)$ :

Group (I): PTN X2 rotary files (25/.06) operated in continuous rotation

Group (II): PTN X2 rotary files operated in reciprocation motion

Group (III): WOG primary (25/.07) rotary files operated in continuous rotation

Group (IV): WOG rotary files operated in reciprocation motion

The rotary files were operated by a torque-controlled motor (X-Smart Plus; Dentsply Maillefer, Ballaigues, Switzerland)

The cyclic fatigue test was conducted in a custommade device that allowed a reproducible simulation of an instrument confined in a curved canal (Fig. 1). The device consisted of curved artificial canal made of

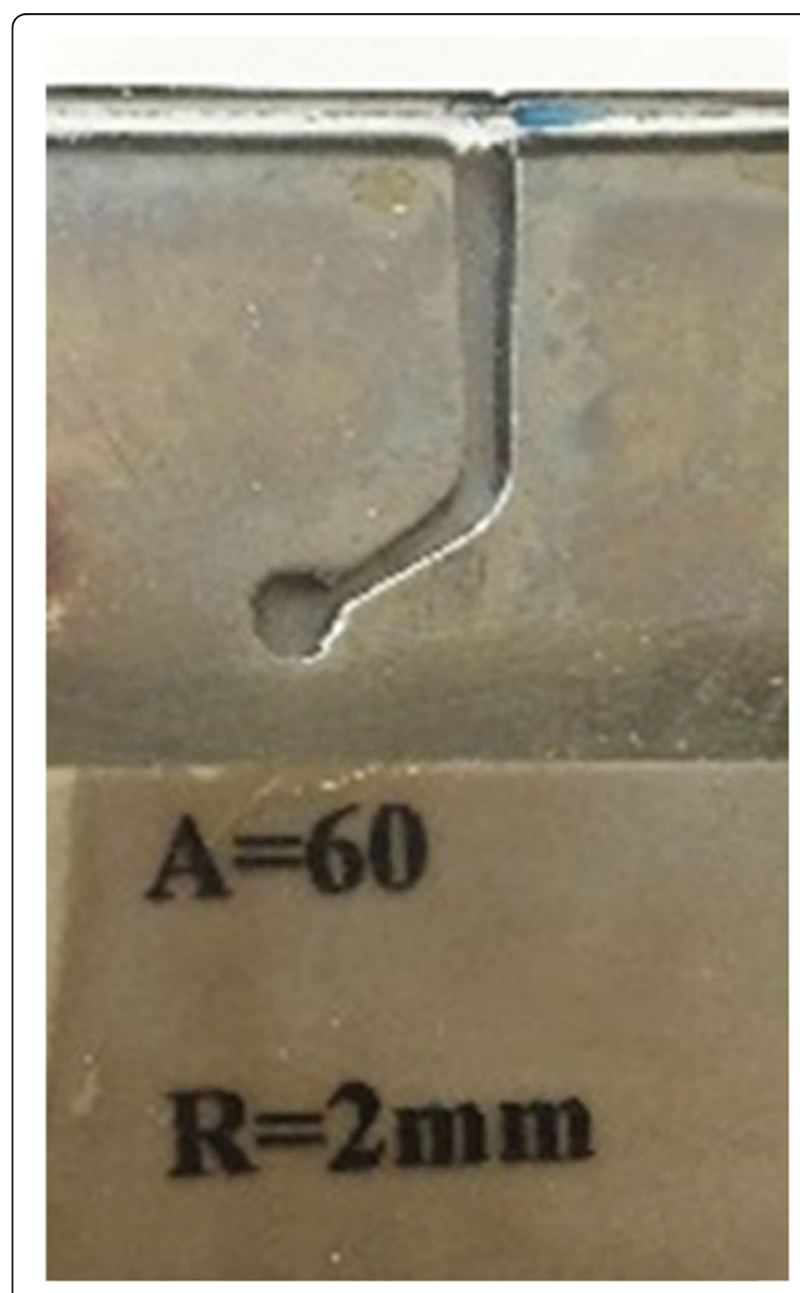

Fig. 1 Custom made cyclic fatigue testing device 
stainless steel with an inner diameter of $1.5 \mathrm{~mm}$, a $60^{\circ}$ angle of curvature, a $2 \mathrm{~mm}$ curvature radius and $19 \mathrm{~mm}$ length. The PTN and WOG instruments were rotated using a torque-controlled motor (X-Smart Plus; Dentsply Maillefer, Ballaigues, Switzerland) at the manufacturers' recommended pre-set speeds and torques; Protaper Next program (300 rpm) for the continuous rotation motion (groups I and III) and the WaveOne ALL program $(350 \mathrm{rpm})$ for the reciprocating motion (groups II and IV).

To reduce the file friction as it contacted the artificial canal walls, a special high-flow synthetic oil intended for lubrication of the mechanical parts (Super Oil; Singer Co. Ltd., Elizabethport, NJ, USA) was applied. All instruments were operated with pecking motion until fracture occurred. The instance of fracture was based on visual observation of the fracture occurring in the instrument. The time to fracture (TTF) was recorded (in seconds) (from starting operating within a canal until fracture occurred) for each instrument with the aid of a 1/100th of a second chronometer, and the timing was stopped as soon as a fracture was detected either visually and/or audibly.

The TTF was converted to the number of cycles to fracture (NCF) by using the following formula: TTF (in seconds $) \times$ rotational speed $(\mathrm{rpm}) / 60$.

\section{Statistical analysis}

Numerical data were explored for normality by checking the data distribution, calculating the mean and median values and using Kolmogorov-Smirnov and ShapiroWilk tests. Data showed parametric distribution so it was represented by mean and standard deviation (SD) values. Two-way ANOVA was used to study the effect of different tested variables and their interaction. Comparison of the main and simple effects was done utilizing pairwise $t$ tests with Bonferroni correction. The significance level was set at $p \leq 0.05$ within all tests. Statistical analysis was performed with IBM (IBM Corporation, NY, USA) SPSS Statistics Version 26 for Windows.

\section{Results}

The mean \pm standard deviation of time in minutes till fracture of different groups are presented in Table 1. Analysis of simple main effects for (TTF) showed that when using either continuous rotation (01:12.60 \pm 00: 13.66) (362.98 \pm 68.29$)$ or reciprocating motion (02: $26.69 \pm 00: 05.67)(855.72 \pm 33.07)$, WOG files showed a significantly higher value of (TTF) and (NCF) than PTN files (00:37.58 $\pm 00: 08.88)(187.89 \pm 44.40)$ in continuous rotation and $(01: 19.55 \pm 00: 10.42)(464.05 \pm 60.80)$ in reciprocating motion respectively $(p<0.001)$. Within each group, the behavior of PTN and WOG in terms of (TTF) and (NCF) values improved significantly in reciprocating motion $(p<0.001)$ (Table 2$)$.

Results of two-way ANOVA test were presented in Table 3. There was a statistically significant interaction between type of file and instrumentation motion utilized $(p=0.003)$. Two-way ANOVA test was conducted to examine the effects of the systems and motion types on the time needed to failure Table 2 and box and bar plots of values of time until fracture in different groups were presented in Figs. 2 and 3, respectively.

\section{Discussion}

Separation of rotary instruments during root canal preparation is considered a critical mishap as the separated segment may hinder the irrigant from entering the canal system that may prevent adequate microorganism eradication (Haapasalo et al. 2003). Thus, considering the factors that may improve the rotary files resistance to cyclic failure is considered a critical issue that has been deeply reviewed in literature (Keskin et al. 2017; Yilmaz et al. 2018). The present study investigated and compared the cyclic fatigue resistances of the PTN and WOG NiTi rotary systems in rotation and reciprocation motions in simulated canal with a $60^{\circ}$ angle of curvature.

Many factors may cause instrument fracture inside the root canal such as canal curvature abruptness including the angle and radius of curvature, the instrument design, surface treatment, and kinematics (Parashos et al. 2004). Variable methods had been utilized to examine the

Table 1 Comparison of simple main effects

\begin{tabular}{|c|c|c|c|c|}
\hline \multirow[t]{2}{*}{ Variable } & \multirow[t]{2}{*}{ Filing motion } & \multicolumn{2}{|c|}{ File type (mean \pm SD) } & \multirow[t]{2}{*}{$p$ value } \\
\hline & & PTN & WOG & \\
\hline \multirow[t]{3}{*}{ TTF } & Continuous rotation & $00: 37.58 \pm 00: 08.88$ & $01: 12.60 \pm 00: 13.66$ & $<0.001^{*}$ \\
\hline & Reciprocation & $01: 19.55 \pm 00: 10.42$ & $02: 26.69 \pm 00: 05.67$ & $<0.001^{*}$ \\
\hline & $p$ value & $<0.001 *$ & $<0.001^{*}$ & \\
\hline \multirow[t]{3}{*}{ NCF } & Continuous rotation & $187.89 \pm 44.40$ & $362.98 \pm 68.29$ & $<0.001^{*}$ \\
\hline & Reciprocation & $464.05 \pm 60.80$ & $855.72 \pm 33.07$ & $<0.001 *$ \\
\hline & $p$ value & $<0.001^{*}$ & $<0.001 *$ & \\
\hline
\end{tabular}

*Significant $(p \leq 0.05)$; $n$ s non-significant $(p>0.05)$ 
Table 2 Descriptive statistics for time till fracture (TTF) (mm:ss:ss) and number of cycles till fracture (NCF) for different groups

\begin{tabular}{|c|c|c|c|c|c|c|c|}
\hline Variable & File type & Motion & Mean & Std. deviation & Median & Min. & Max. \\
\hline \multirow[t]{4}{*}{ TTF } & PTN & Continuous rotation & $00: 37.58$ & $00: 08.88$ & $00: 33.00$ & $00: 29.45$ & $00: 49.00$ \\
\hline & & Reciprocation & $01: 19.55$ & $00: 10.42$ & 01:20.39 & 01:04.27 & $01: 30.00$ \\
\hline & WOG & Continuous rotation & 01:12.60 & $00: 13.66$ & 01:05.69 & $00: 58.45$ & $01: 28.89$ \\
\hline & & Reciprocation & 02:26.69 & 00:05.67 & $02: 25.10$ & $02: 20.00$ & $02: 35.07$ \\
\hline \multirow[t]{4}{*}{ NCF } & PTN & Continuous rotation & 187.89 & 44.40 & 165.00 & 147.25 & 245.00 \\
\hline & & Reciprocation & 464.05 & 60.80 & 468.94 & 374.91 & 525.00 \\
\hline & WOG & Continuous rotation & 362.98 & 68.29 & 328.45 & 292.25 & 444.45 \\
\hline & & Reciprocation & 855.72 & 33.07 & 846.42 & 816.67 & 904.58 \\
\hline
\end{tabular}

cyclic fatigue fracture resistance of NiTi rotary files. In the present study, a custom-made canal model was employed to keep the experimental conditions standardized in terms of angle and radius of curvature and minimize the impact of other variables (Pruett et al. 1997). The simulated canal design used in the study followed the approach illustrated by Pruett et al. (Pruett et al. 1997). The custom-made canal had an angle of curvature of $60^{\circ}$, a radius of curvature of $3 \mathrm{~mm}$, to simulate the abrupt apical root canal curvature, where the maximum stresses are concentrated on the rotary instruments (Chang et al. 2016; Pedullà et al. 2012). A pecking motion was employed during the instrumentation procedures to prevent instrument binding and torquegenerated cyclic fatigue (Li et al. 2002).

According to the findings of the study, the WOG file showed significantly higher cyclic fatigue resistance than that of PTN in both the continuous rotation and reciprocation modes $(p<0.001)$; thus, the null hypothesis was rejected. Though WOG was never tested in continues rotating motion, the findings of this study correspond with previous studies reporting that the WOG files were significantly more cyclic fatigue resistant compared to other files tested in reciprocating motions (Elnaghy and Elsaka 2014; Ozyurek 2016).
This outcome could be attributed to the difference in the metallurgical properties and the cross-sectional designs of the tested NiTi systems which have an impact on cyclic fatigue resistance (Berutti et al. 2012). The WOG files are made of thermally treated $\mathrm{Ni}-\mathrm{Ti}$ alloy termed "Gold", where the ground instrument is heattreated then slowly cooled in a post-manufacturing process. This process results in a characteristic gold finish that enhances its resistance to fracture and flexibility and reduces the surface defects (Sirona n.d.). The WOG files have a parallelogram cross-section, two cutting edges, and an alternate contact point. This design feature reduces the number of contact points between the WOG file and the canal walls. While, PTN is made of $\mathrm{M}$-wire, that has improved resistance to cyclic fatigue through a proprietary of thermomechanical process the material has undergone during manufacturing. The PTN files have an off-centered rectangular cross-sectional design (Ye and Gao n.d.).

In this study, applying the reciprocating motion on both files significantly increased the time until failure $(p$ $<0.001)$. In this research, the reciprocating motion was delivered by using the X-Smart Plus endodontic motor utilizing the preset-mode (WAVEONE ALL) and the continuous rotation motion through Protaper Next

Table 3 Two-way ANOVA test results

\begin{tabular}{|c|c|c|c|c|c|c|}
\hline Variable & Source & Sum of squares & df & Mean square & $f$ value & $p$ value \\
\hline \multirow[t]{4}{*}{ TTF } & File type & 13045.83 & 1 & 13045.83 & 128.47 & $<0.001 *$ \\
\hline & Filing motion & 16840.89 & 1 & 16840.89 & 165.84 & $<0.001^{*}$ \\
\hline & File type $*$ motion & 1289.94 & 1 & 1289.94 & 12.70 & $0.003^{*}$ \\
\hline & Error & 1624.79 & 16 & 101.55 & & \\
\hline \multirow[t]{4}{*}{ NCF } & File type & 401509.31 & 1 & 401509.31 & 140.56 & $<0.001^{*}$ \\
\hline & Filing motion & 739005.81 & 1 & 739005.81 & 258.71 & $<0.001^{*}$ \\
\hline & File type ${ }^{*}$ motion & 58629.11 & 1 & 58629.11 & 20.52 & $<0.001 *$ \\
\hline & Error & 45703.63 & 16 & 2856.48 & & \\
\hline
\end{tabular}




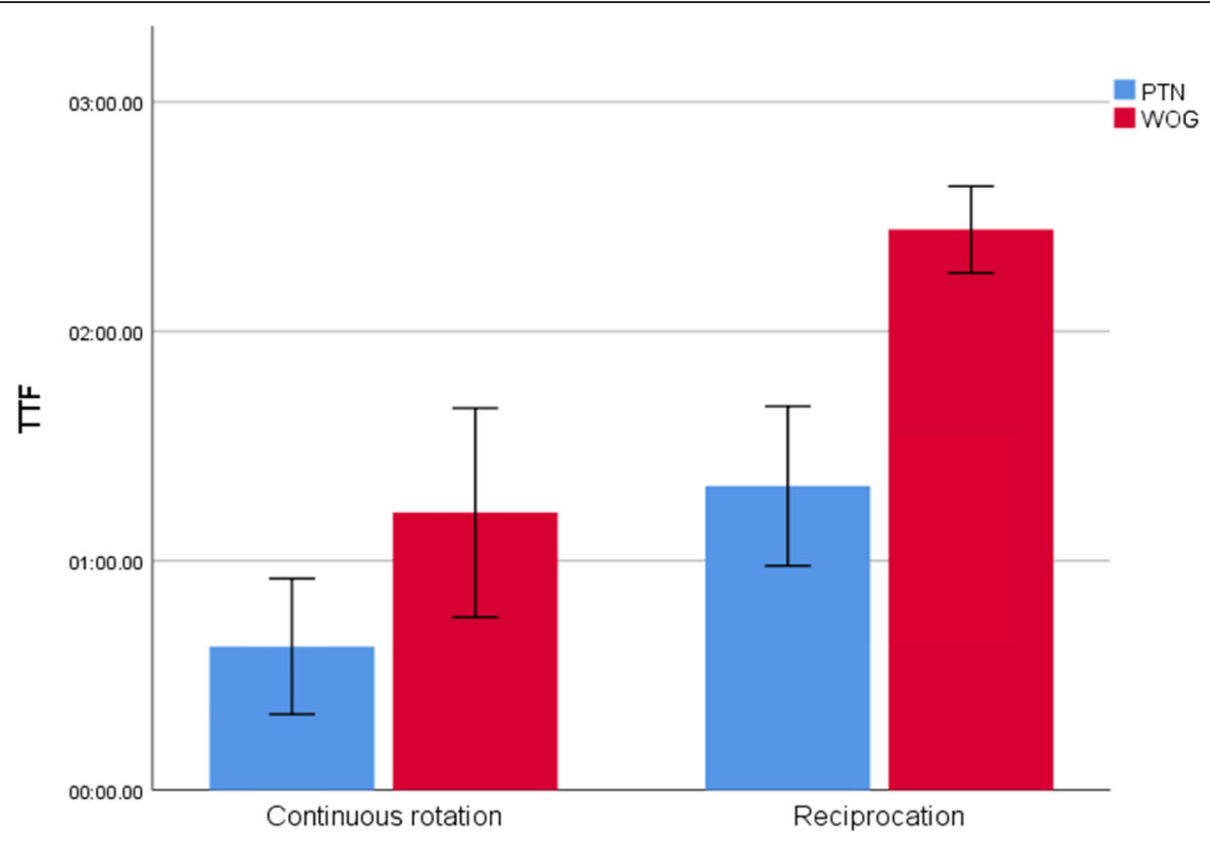

Fig. 2 Bar chart showing mean and standard deviation values of time till fracture (TTF) (mm:ss:ss) in different groups

Mode. Both are pre-programmed modes, with the speed and the torque of the rotating files are not influenced by the operator. No previous study had operated the WOG in continuous rotation or the PTN in reciprocating motion. An important feature in the performance of the reciprocating instruments is the reciprocation range. The manufacturer of WaveOne rotary system suggests a range of 150 counter-clock wise/30 Clockwise that completes one cutting cycle in three strokes (Saber and ElSadat 2013). The literature demonstrated the significant increase in the cyclic fatigue resistance of the NiTi files operated in reciprocating motion when compared to continuous rotation (Castelló-Escrivá et al. 2012; Plotino et al. 2015; Pedullà et al. 2013). Cyclic fatigue resistance is affected by the number of cumulative cycles of tension and compression created while operating in

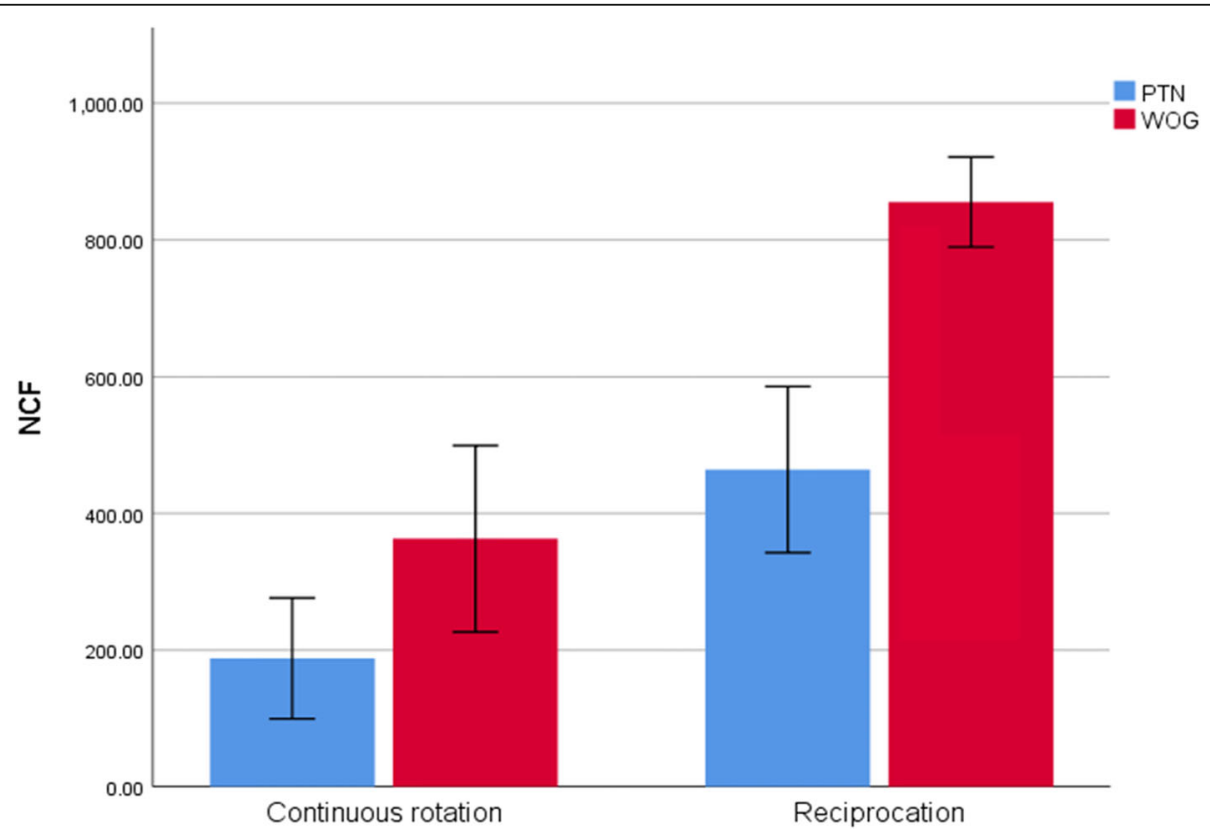

Fig. 3 Bar chart showing mean and standard deviation values of number of cycles till fracture (NCF) in different groups 
the curved part of the instrument (Inan et al. 2007). Many studies revealed that the time of fracture is attributed to the rotation speed, i.e., instruments show more resilience when operated at lower speeds ( $\mathrm{Li}$ et al. 2002). According to the manufacturer, the WaveOne system operates in clockwise/counter-clockwise directions at $350 \mathrm{rpm}$ as a speed, with $120^{\circ}$ difference between the two motions (Gavini et al. 2012; Bürklein et al. 2012). Although the continuous rotary system has a lower rotational speed of $300 \mathrm{rpm}$, reciprocation motion shows non-constant rotational speed during operation, as the electric motor shows some limitations in altering the direction of rotation mechanically, unlike what happens in the case of continuous rotation (Kim et al. 2012). Thereby, less tension is created on the file while rotating in both directions due to the procedure of acceleration/ deceleration and consequently better cyclic fatigue resistance ( $\mathrm{Li}$ et al. 2002). In agreement with You et al. (You et al. 2010) who stated that the increased longevity of the instruments was associated with their decreased binding capacity to root canal dentin. Rubio et al. (Rubio et al. 2019) showed that systems with Gold-Wire alloys and reciprocating motion offered better resistance to cyclic fatigue. They reported superior cyclic fatigue resistance performance of WOG. Reciprocating motion was found to improve the cyclic fatigue results compared to almost all the continuous motion systems studied

Pedulla et al. (Pedullà et al. 2013), Lee et al. (Lee et al. 2013), Gambarini et al. (Gambarini et al. 2012), and Kiefner et al. (Kiefner et al. 2014) utilized the same file system with different kinematics. They showed that cyclic fatigue is affected by kinematics and that the reciprocating motion had better cyclic fatigue resistance than its counterpart.

\section{Conclusions}

Within the parameters of this in vitro study, it could be concluded that reciprocating motion showed superior cyclic fatigue resistance than continuous rotation. In addition, WOG files showed significantly longer time till fracture than PTN files. WOG operated with reciprocating motion showed the best performance in terms of cyclic fatigue resistance. PTN showed enhanced cyclic fatigue resistance when operated in reciprocating motion. Finally, reciprocating motion can be utilized more safely in curved canals than continuous rotation due to the better cyclic fatigue resistance performance.

\section{Abbreviations}

NiTi: Nickel-titanium; WOG: WaveOne Gold; PTN: Protaper Next; TTF: Time till fracture; NCF: Number of cycles till fracture

Acknowledgements

Not applicable

\section{Authors' contributions}

$\mathrm{AGl}, \mathrm{MG}$, and NNR contributed to the conception and design of the study, experimental work, interpretation of the analyzed data, writing the manuscript, revised and reviewed the draft manuscript. All authors have read and approved the final manuscript.

\section{Funding}

The work was self-funded by the authors.

\section{Availability of data and materials}

All data generated or analyzed during this study are included in this published article.

Ethics approval and consent to participate

Not applicable.

Consent for publication

Not applicable.

\section{Competing interests}

The authors declare that they have no competing interests.

\section{Author details}

'Restorative and Dental Materials Department, National Research Centre (NRC), El Bohouth St., 12622 Dokki, Giza, Egypt. 'Endodontic Department, Faculty of Dentistry, Cairo University, Giza, Egypt.

Received: 27 August 2020 Accepted: 9 September 2020

Published online: 18 September 2020

\section{References}

Berutti E, Chiandussi G, Paolino DS et al (2012) Canal shaping with WaveOne Primary reciprocating files and ProTaper system: a comparative study. J Endod 38:505-509

Bürklein S, Hinschitza K, Dammaschke T, Schäfer E (2012) Shaping ability and cleaning effectiveness of two single-file systems in severely curved root canals of extracted teeth: Reciproc and WaveOne versus Mtwo and ProTaper. Int Endod J 45:449-461

Castelló-Escrivá R, Alegre-Domingo T, Faus-Matoses V, Román-Richon S, FausLlácer VJ (2012) In vitro comparison of cyclic fatigue resistance of ProTaper, WaveOne, and Twisted Files. J Endod 11:1521-1524

Chang SW, Shim KS, Kim YC, Jee KK, Zhu Q, Perinpanayagam H, Kum KY (2016) Cyclic fatigue resistance, torsional resistance, and metallurgical characteristics of $V$ taper 2 and $V$ taper $2 \mathrm{H}$ rotary NiTi files. Scanning 38:564-570 PUBMED | CROSSREF

Elnaghy AM, Elsaka SE (2014) Assessment of the mechanical properties of ProTaper next nickel-titanium rotary files. J Endod 11:1830-1834

Gambarini G, Gergi R, Naaman A et al (2012) Cyclic fatigue analysis of twisted file rotary NiTi instruments used in reciprocating motion. Int Endod J 45:802-806

Gavini G, Caldeira CL, Akisue E, Candeiro GT, Kawakami DA (2012) Resistance to flexural fatigue of Reciproc R25 files under continuous rotation and reciprocating movement. J Endod 38:684-687

Haapasalo M, Udnaes T, Endal U (2003) Persistent, recurrent, and acquired infection of the root canal system posttreatment. Endod Top 6(1):29-56

Inan U, Aydin C, Uzun O, Topuz O, Alacam T (2007) Evaluation of the surface characteristics of used and new ProTaper instruments: an atomic force microscopy study. J Endod 33:1334-1337

Karataş E, Arslan H, Büker M, Seçkin F, Çapar ID (2016) Effect of movement kinematics on the cyclic fatigue resistance of nickel-titanium instruments. Int Endod J 49:361-364

Keskin C, Inan U, Demiral M, Keles A (2017) Cyclic fatigue resistance of reciproc blue, reciproc, and WaveOne gold reciprocating instruments. J Endod 43(8): 1360-1363

Kiefner P, Ban M, De-Deus G (2014) Is the reciprocating movement per se able to improve the cyclic fatigue resistance of instruments? Int Endod J 47:430-436

Kim HC, Kwak SW, Cheung GSP, Ko DH, Chung SM, Lee WC (2012) Cyclic fatigue and torsional resistance of two new nickel-titanium instruments used in reciprocation motion: reciproc versus WaveOne. J Endod 38:541-544

Lee W, Hwang YJ, You SY, Kim HC (2013) Effect of reciprocation usage of nickeltitanium rotary files on the cyclic fatigue resistance. Aust Endod J 39:146-150 
Li UM, Lee BS, Shih CT et al (2002) Cyclic fatigue of endodontic nickel-titanium rotary instruments: static and dynamic tests. J Endod 28:448-451

Ozyurek T (2016) Cyclic fatigue resistance of Reciproc, WaveOne, and WaveOne gold nickel-titanium instruments. J Endod 42:1536-1539

Parashos P, Gordon I, Messer HH (2004) Factors influencing defects of rotary nickel-titanium endodontic instruments after clinical use. J Endod 30:722-725

Parashos P, Messer HH (2006) Rotary NiTi instrument fracture and its consequences. J Endod 32:1031-1043

Pedullà E, Grande NM, Plotino G, Gambarini G, Rapisarda E (2013) Influence of continuous or reciprocating motion on cyclic fatigue resistance of 4 different nickel-titanium rotary instruments. J Endod 2:258-261

Pedullà E, Plotino G, Grande NM, Pappalardo A, Rapisarda E (2012) Cyclic fatigue resistance of four nickeltitanium rotary instruments: a comparative study. Ann Stomatol (Roma) 3:59-63

Peters OA (2004) Current challenges and concepts in the preparation of root canal systems: A review. J Endod 30:559-567

Plotino G, Ahmed HM, Grande NM, Cohen S, Bukiet F (2015) Current assessment of reciprocation in endodontic preparation: A comprehensive review-Part II: Properties and effectiveness. J Endod 41:1939-1950

Plotino G, Grande NM, Testarelli L, Gambarini G (2012) Cyclic fatigue of Reciproc and WaveOne reciprocating instruments. Int Endod J 45:614-618

Pruett JP, Clement DJ, Carnes DL Jr (1997) Cyclic fatigue testing of nickeltitanium endodontic instruments. J Endod 23(February (2)):77-85

Rubio J, Zarzosa Jl, Pallarés A (2019) A Comparative Study of Cyclic Fatigue of 10 Different Types of Endodontic Instruments: an in Vitro Study. Acta Stomatol Croat 53(1):28-36

Saber SEMS, ElSadat SM (2013) Effect of Altering the Reciprocation Range on the Fatigue Life and the Shaping Ability of WaveOne Nickel-Titanium Instruments. J Endod 39:685-688

Sattapan B, Nervo GJ, Palamara JE, Messer HH (2000) Defects in rotary nickeltitanium files after clinical use. J Endod 26:161-165

Shen Y, Zhou HM, Zheng YF, Peng B, Haapasalo M (2013) Current challenges and concepts of the thermomechanical treatment of nickel-titanium instruments. J Endod 39:163-172 8

Denstply Sirona. The WaveOne Gold Brochure. https://www.dentsplysirona.com/ content/dam/dentsply/pim/en_GB/Endodontics/Obturation/Paper_Points/ WaveOne_Gold_Absorbent_Points/WaveOne\%20GOLD\%20Brochure\%202 015.pdf. [Last accessed on 2018 Feb 01].

Webber J (2015) Shaping canals with confidence: WaveOne GOLD single-file reciprocating system. Roots 1:34-40

Ye J, Gao Y. Metallurgical characterization of M-wire nickel-titanium shape memory alloy used for endodontic rotary instruments during low-cycle fatigue J Endod. 2012;38(1):105-7. https://doi.org/10.1016/j.joen.2011.09.028. Epub 2011 Nov 9

K. Yilmaz, G. Uslu, M. Gundogar, T. Ozyurek, N. M. Grande, " and G. Plotino, "Cyclic fatigue resistances of several nickeltitanium glide path rotary and reciprocating instruments at body temperature," Int Endod J, vol. 51, no. 8 , pp. 924-930, 2018

You SY, Bae KS, Baek SH et al (2010) Lifespan of one nickel-titanium rotary file with reciprocating motion in curved root canals. J Endod 36:1991-1994

\section{Publisher's Note}

Springer Nature remains neutral with regard to jurisdictional claims in published maps and institutional affiliations.

\section{Submit your manuscript to a SpringerOpen ${ }^{\circ}$ journal and benefit from:}

- Convenient online submission

- Rigorous peer review

- Open access: articles freely available online

- High visibility within the field

- Retaining the copyright to your article

Submit your next manuscript at $\boldsymbol{\nabla}$ springeropen.com 